\title{
The Influence of Leadership Competencies on Sustainable Funding of Local Non-Governmental Organizations in Uganda
}

\author{
Paul Kyalimpa (Corresponding Author) \\ Institute of Management Sciences, Mbarara University of Science, and Technology \\ PO Box 1410, Mbarara, Uganda. \\ E-mail: askyalimpa@gmail.com
}

John Baptist Asiimwe

Bishop Stuart University, 09, Mbarara, Uganda.

Fulufhelo Godfrey Netswera \& Edward Malatse Rankhumise

Tshwane University of Technology, Pretoria, South Africa.

Received: August 1, 2017 Accepted: August 18, 2017 Online published: September 8, 2017

doi:10.5296/jpag.v7i3.11824 URL: https://doi.org/10.5296/jpag.v7i3.11824

\begin{abstract}
Introduction. When a leader with a vision launches a Local Non-Governmental Organization (LNGO or NGO), the NGO's motivation and decision-making often become intertwined with the leader's personality and character to the effect that it may collapse when the NGO leader departs. Uganda has a higher percentage of NGOs inactivity and mortality due to unsustainable funding. Therefore, this study investigated the influence of NGO leadership competencies on sustainable funding of NGOs.

Methods. This study utilized a descriptive correlation design. A proportionate stratified sample of 103 NGOs was obtained and their leaders were interviewed using self-administered questionnaires. Records reviews were conducted to obtain data on NGO funding.

Results. This study found a $90.1 \%$ to $100 \%$ agreement by participants on possession of the various leadership competencies by the NGO leaders. A marked rise in NGO incomes from all sources was recorded between 2010 and 2014, with external donors, local donors, and
\end{abstract}


own income accounting for $67 \%, 13.5 \%$, and $19.5 \%$ of the total funds, respectively. The average donor-dependency ratio and survival ratio over the 5 year period was $80.54 \%$ and 71.216 days respectively. The NGO leader understanding and working with whatever resources that are available $(\beta=-9.802, P=.002)$ and spearheading the implementation of major investment decisions $(\beta=15.720, P=.004)$ were the only competencies found to be statistically significant predictors of NGO financial sustainability.

Recommendations. Government funding of NGOs, prioritization of Income Generating Activities and capacity building of NGO leaders in effective and efficient resource utilization and investment by NGOs, are crucial to NGO Survival.

Keywords: Leadership Competencies, Sustainable Funding, Local NGOs

\section{Introduction}

The last decade has been marked by an increased involvement of NGOs in the development process due to the failure of development assistance to governments of poor countries, to generate growth or to reach the poor. On the other hand, the success of non-governmental initiatives, especially the Grameen Bank in Bangladesh put forward as a model, has been put forth in development circles as an illustration of NGO potential to better deliver the much-needed development to the poor (Barr, Fafchamps, \& Owens, 2003). In the African continent where governments' capacity and revenue are often very limited to deliver the much-needed services to the public, NGOs play a pivotal role to poverty alleviation.

Despite the above contribution, the NGO sector remains highly dependent on external donor funding. The findings of the NGO Sustainability Index for Sub-Sahara Africa (2009) revealed that while NGOs' ability to provide service to underserved populations had the highest score in all 19 countries sampled in Africa including Uganda, funding sustainability was the weakness. A common issue for many NGOs in sub-Sahara Africa, Uganda at the heart, is reliance on a single, external source for funding. While reliance on the external source of funding is reflective of the wider economic context of African countries, in this situation, if international funding were to disappear, many of the NGOs would collapse (USAID, 2010). Imperative to note is that scholars on the sustainability of NGOs, including Manyeruke (2012), concurred that sustainable funding remained one of the major challenges that NGOs in Africa faced and will continue to face in the next decade.

A study by the Office of the Prime Minister in 2003 about the NGO sector in Uganda found that between $15-30 \%$ of the NGOs that register go operational (Barr, Fafchamps \& Owens 2003). This was attributed to failure to successfully mobilize funding to commence operations. An NGO funding sustainability is paramount as it enables it to survive so that it can continue to serve its citizenry. This means that an organization will be able to fulfill commitments to "its clients, its patrons, and the community in which it operates" so that the groups who depend on it can "place their trust in that commitment" (Weerawardena et al., 2009 , p. 2). The research findings on the role of Non-Governmental Organizations (NGOs) in social development in Uganda revealed that the major limitations of NGOs' Contribution to Development are inadequate funding of NGO Activities, NGO dependency on external donor 
funding and non-sustainability of NGO activities (Wamai, Walera, and Wamai, 2007). Additionally, the study findings of NORAD (2002), indicated that the character and role of the majority of NGOs in Uganda are influenced by among other factors such as availability of funds and interests of funders/donors. In Uganda, availability of donor funds is a stronger pull factor for individuals starting an NGO and has a more dominant influence on sustainability (Sanjeev, Powell \& Yang, 2006). In such situations, if international funding were to disappear, many of the NGOs would collapse.

In the study of NGO sustainability, it is imperative to consider the influence of organizational mission and leadership, which are central concepts in the description of NGOs (Burger \& Owens, 2012). NGOs mission and drive have been found to be intimately linked to charismatic leadership to the extent that when an individual launches an NGO, the organization's motivation and decision-making often become so intimately intertwined with the leader's personality and character to the effect that the NGO may collapse when the leader departs (Burger \& Owens 2012; Sooryamoorthy \& Gangrade, 2001). Research in leadership has established typical competencies commonly associated with NGO leaders and these include the ability of a leader to initiate, communicate, and implement a mission and vision, fundraising, staff empowerment and responsiveness to changing the environment (Burger \& Owens, 2012; Sooryamoorthy \& Gangrade 2001). According to research conducted in the UK, NGO leaders exhibited an unusually broad range of competencies compared to leaders in the public and private sectors (Bolton \& Abdy, 2003).

Despite the fact that, little research has been conducted to link leadership competencies and financial sustainability, there have been some efforts to promote leadership competence development by many international NGOs. For example, the International Federation of the Red Cross and Save the Children Alliance have created assessment tools that try to capture leadership competencies based on the individual leader's ability to envision (create and communicate individual strategy), enable (identify and apply appropriate tools, processes, and people), empower (develop effective teams), and energize (communicate and inspire) through personal leadership (Hailey, 2006). In addition, there have been interventions geared towards developing a new generation of NGO leaders that among other will foster sustainability. This is reflected by the increasing investment of international development agencies such as Save the Children Fund, Organization Development Department of the International Federation of the Red Cross, CARE International, and a consortium of US-based NGOs in Leadership Development Programs (LDPs) (James, 2005a; Hailey \& James 2004; Lewis 2001). These interventions though limited, point to increasing funding for leadership competence development as well as a growing awareness of the importance of developing the role and skills of NGO leaders.

Despite their prominent role and capacity building interventions on leadership, no research has been done on the competencies that affect the survival of NGOs and the influence that their leadership exerts towards their sustainability. Because of the limited reach on the survival of NGOs and influence of leadership, existing literature also reveals that the work that does exist is piecemeal and based on case studies (Burger \& Owens, 2012). Specifically, there is no empirical evidence on the competencies of NGO leaders in Uganda and the extent 
to which these competencies influence their sustainable funding. This research, therefore, investigated the competencies of NGO leaders and the extent to which they influence sustainable funding as a step towards reducing the high level of donor dependency that makes Uganda's NGO sector very fragile and poses a threat to the sustainability of its activities.

\section{Methods}

\subsection{Sample and Procedure}

The survey was conducted among NGOs from all the four regions of Uganda over a three-month period (August to November 2016). Five hundred and seventy-two (572) NGOs who were registered as of November 2016 with Uganda National NGO Forum (UNNGOF) database formed the study population. The Uganda National NGO Forum database is the only umbrella forum that is independent, inclusive and a coordinating national platform for all registered NGOs and their members are from all the various programmatic sectors, and regions of the country and membership is voluntary. For studying smaller target populations, with a sample size of less than 1000, Mugenda and Mugenda (2003) recommends a sample size of at least $10 \%$ of the total target population as satisfactory, although, for comprehensive data analysis and large statistical power, this can range from $10 \%$ to $30 \%$ or even larger. This study utilized a sample size of 103 NGOs, which constituted about $18 \%$ of the study population (572). Using the four regions as strata, proportionately stratified sampling procedures were used to distribute the sample size above, depending on the percent registration of NGOs per region on the UNNGOF database. To carter for the non-response rate, five (5) extra NGOs per region were randomly selected and invited to participate in the study.

During the data collection phase, the research assistants were trained in the administration of this study research tool. At the NGO site, the research assistant gave a self-administered semi-structured questionnaire to the NGO leaders (study participants) after introducing the study to them and obtaining consent from them. Those selected to participate in this study were senior staff who knew the financial status of the organizations and these included executive directors, program managers, and finance managers. Senior staff members who were not available during the period of the study, such as those on leave (maternity, sick, and study) were not included in the study. The research assistant also obtained consent from NGO leaders to access the financial records in the finance sections/departments, in order to fill in the financial aspects of the questionnaire. Records that were reviewed included the audit reports, annual financial performance reports, and signed contracts. Approval to conduct this study was obtained from Mbarara University institutional research review board.

\subsection{Rigor}

The questionnaire was pretested with a selected pilot group of ten (10) NGO representatives. Feedback from the pre-test was used to improve the design of the final tools for this study. In reliability analyses, internal consistency of the tool was evaluated using Cronbach alpha (Table 1). Alpha values of 0.7 or higher were considered acceptable (Sweet \& Martin, 2008). Where alpha was below 0.7 , items were deleted based on their ability to increase the alpha 
values above 0.7 . Item analyses were also conducted testing each item's association with other items (inter- item correlations-IIC) and with the total item scores (corrected item total correlations-ITC). The findings of this study were based on 23 items, with an overall Cronbach alpha of .857 and MIIC of .212 (Table 1).

Table 1. Internal Consistency and Measurement Properties of Items

\begin{tabular}{lllll}
\hline Competencies & $\begin{array}{l}\text { Item } \\
(\mathbf{N})\end{array}$ & $\begin{array}{l}\text { MIIC } \\
\text { Overall }\end{array}$ & $\begin{array}{l}\text { Cronbach's } \\
\boldsymbol{\alpha}\end{array}$ & NIIC>0.30 \\
\hline Strategic, Financial and Investment Planning & 3 & .212 & .857 & 19 \\
Considerations & & .629 & .834 & 3 \\
Investment Considerations & 2 & .716 & .834 & 2 \\
Fundraising Strategy Considerations & 2 & .739 & .850 & 2 \\
Income Diversification Considerations & 2 & .655 & .791 & 2 \\
Funding Partners & 2 & .661 & .795 & 2 \\
Income Generating Activities & 2 & .753 & .859 & 2 \\
Responsiveness & 4 & .646 & .879 & 4 \\
Attributes of NGO Leader & 2 & .548 & .707 & 2 \\
Empowerment & 2 & .3955 & .667 & 2 \\
Motivation of Staff & 2 & .611 & .755 & 2 \\
\hline
\end{tabular}

Note. Mean inter-item correlation (MIIC), Inter- item correlations-IIC, number of items with NIIC $>0.30$ (positive correlation of 0.30 or more are desirable). For items less than 10, Cronbach alpha could be smaller and thus the MIIC (acceptable range, 0.2-0.4) is a better measure of internal consistency.

\subsection{Measures}

\subsubsection{Dependent variables}

Lewis (2009) lays down financial measures NGOs could use to measure financial sustainability and those used in this study included dependency ratios and survival ratios (Sharma, 2012). The donor dependency Ratio is a measure of the organization's donor income to the total income generated during the year. In this study, a higher NGO donor dependency ratio was interpreted as that NGO being financially unsustainable and vice versa and this was calculated as follows: Donor Income/Total Income* 100 (Results expressed in percentages (\%). On the other hand, survival ratios are an indicator of how long an organization can survive if all its funds are dried up and there are no donations received during the year (Sharma, 2012) and the higher the NGO survival ratio, the higher likelihood that the NGO is financially sustainable and vice versa. Survival ratios were calculated as follows: General Reserves/Total Income*52 or 365 (Results expressed in days). In addition, the total average income computed from local donors, external donors, and income generating activities (IGA) incomes of NGOs were also examined in this study as a measure of financial sustainability. This outcome was interpreted as the higher the income an NGO obtained from all sources over a period of five years, the more likely that organization was sustainable and vice versa. 


\subsubsection{Independent Variables}

The first group of independent variables was the leadership competencies. Participants were requested to rate their level of agreement with statements regarding various categories of competencies: Strategic, financial and Investment planning considerations (6 items), investment considerations ( 3 items), fundraising strategy considerations (3 items), Income diversification considerations ( 3 items), funding partners ( 3 items), income generating activities (3 items), responsiveness (4 items), attributes of NGO leader (3 items), empowerment (3 items), motivation of Staff (3 items), and teamwork ( 3 items). As shown in table 1 , the final items analyzed were 23 . Response alternatives were recorded and entered as follows: To a very great extent $=5$, to a great extent $=4$, to a moderate extent $=3$, to a little extent=2, not at all=1. High values indicated a highly held opinion about how the Participants perceived NGO leader's competencies in their respective NGOs'.

The second group of independent variables was the NGO and participant characteristics. These groups of variables were included in multivariate analyses to control for spurious relationships that may have occurred between leadership competencies and financial sustainability measures. These variables were measured at the nominal and ordinal level and are shown in Table 2.

\subsection{Data Analysis}

Data was entered and analyzed using SPSS (vs 20). Preliminary analyses were conducted to ensure no violation of the assumptions of normality, linearity, multicollinearity, and homoscedasticity. However, dependent variables were skewed, even after log transformation, but due to a large sample size $(n=103)$, parametric tests were conducted.

Frequencies and percentages were calculated for each of the categorical variables. The relationship between the leadership competencies and sustainable funding measures were examined using Pearson product-moment correlation coefficient. A correlation of 0.30 or above was considered a "good correlation" and a correlation above 0.4 was considered "a strong correlation" (Sweet \& Martin, 2008). Correlations reported were significant at 0.05 or 0.01 .

Independent Variables that significantly correlated with the dependent variables were entered into bivariate linear regression in order to obtain the explanatory and predictive power of each of the independent on dependent variables. The explanatory power of the model/independent variables on the dependent variables was presented as an adjusted $\mathrm{R}$ square $\left(R^{2}\right)$. Meanwhile, the predictive power of the independent variables on the dependent variables was presented as unstandardized coefficients $(\beta)$. Coefficients reported were significant at 0.05 or 0.01 .

Independent variables that were significant in bivariate linear regression were entered into the standard multivariate linear regression to establish the final independent variables that have an influence on financial sustainability measures. Variables that were not significant in the regression model were eliminated until a final model with all the variables significant was obtained. 


\section{Macrothink}

\section{Results}

\subsection{Sample Characteristics}

The demographic characteristics of the sample are presented in Table 2. One hundred and three (103) NGO staff participated in this study. The majority of the participants were heads of programs $(54 \%)$. About $80.2 \%$ of all the participants had graduate and postgraduate qualifications. However, the majority of the participants had less 5 years' experience in the NGO sector (55\%) and had worked for less than five years in their current NGO's $(78.2 \%)$. This study also found out that the majority of the NGO's were founded by group members (48.5\%) followed by the chief executive officers (45.4\%). Lastly, the NGOs' governance was majorly under the hands of the CEO's (46.5\%) followed by the board of director $(41.4 \%)$, and management committees $(10.1 \%)$.

Table 2. Participants' Profile

\begin{tabular}{ll}
\hline Variables & $\boldsymbol{n}(\boldsymbol{\%})$ \\
\hline Position of Participants & $54(54)$ \\
Head of Programs & $44(44)$ \\
Head of Finance/Resource Mobilization & $2(2)$ \\
Any Other & \\
Level of Education & $3(3)$ \\
Certificate and below & $17(16.8)$ \\
Diploma & $43(42.6)$ \\
Graduate & $38(37.6)$ \\
Post graduate Education & \\
Experience with the NGO Sector & $55(55)$ \\
5 and <Years & $45(45)$ \\
6 and >Years & \\
Duration at Current NGO & $79(78.2)$ \\
5 and <Years & $22(21.8)$ \\
6 and >Years & \\
Founder of NGO & $44(45.4)$ \\
NGO Leader & $3(3.1)$ \\
Another Individual & $47(48.5)$ \\
Group of Members & $3(3.1)$ \\
Any Other & \\
Who Currently Runs the NGO & $46(46.5)$ \\
CEO & $41(41.4)$ \\
Board of Directors & $10(10.1)$ \\
Management Committee/team & $2(2)$ \\
Any Other &
\end{tabular}




\subsection{NGO Characteristics}

The majority of NGOs' were local by nature (73.5\%) and from western Uganda $35.3 \%$, See Table 3). About $89.2 \%$ of the NGOs had less than four programmatic areas of operations. On the other hand, $88.2 \%$ and $85.3 \%$ of the NGOs' surveyed had active strategic and financial plans respectively. Unfortunately, a bare majority of NGOs' $(55.4 \%)$ had a fundraising strategy to support their financial plans. When it came to the question, of either, the NGO invests or not and whether it has an investment plan or not, only $50 \%$ and $21.9 \%$ of the NGOs' invested and had an investment plan respectively. On a positive note, among those NGOs with plans and strategies mentioned in this section, $81.1 \%, 74.7 \%, 75.9 \%$, and $73.3 \%$ had long-term strategic plans, financial plans, fundraising strategy, and investment plans respectively.

Table 3. NGO Characteristics

\begin{tabular}{|c|c|}
\hline Variables & $n(\%)$ \\
\hline \multicolumn{2}{|l|}{ Type of NGO } \\
\hline Trust & $2(2)$ \\
\hline Private Voluntary Organization (PVO) & $8(7.8)$ \\
\hline Local NGO & $75(73.5)$ \\
\hline National NGO (all Regions) & $12(11.8)$ \\
\hline Local \& International & $5(4.9)$ \\
\hline \multicolumn{2}{|l|}{ Region } \\
\hline Central & $13(12.7)$ \\
\hline North & $25(24.5)$ \\
\hline East & $11(10.8)$ \\
\hline West & $36(35.3)$ \\
\hline Four regions & $13(12.7)$ \\
\hline 2 and 3 regions & $4(3.9)$ \\
\hline \multicolumn{2}{|c|}{ No. of Thematic Areas/ Programmatic Sectors } \\
\hline $1-2$ & $39(38.2)$ \\
\hline $3-4$ & $52(51)$ \\
\hline $5+$ & $11(10.8)$ \\
\hline \multicolumn{2}{|l|}{ Presence of an Active Strategic Plan } \\
\hline Yes & $90(88.2)$ \\
\hline No & $12(11.8)$ \\
\hline \multicolumn{2}{|l|}{ Duration of the Strategic Plan } \\
\hline 1-2 years "Short term" & $2(2.2)$ \\
\hline 3-4 years "Medium term" & $5(5.6)$ \\
\hline 5 and above "Long term" & $73(81.1)$ \\
\hline Expired & $10(11.1)$ \\
\hline \multicolumn{2}{|l|}{ Presence of Financial Plan } \\
\hline Yes & $87(85.3)$ \\
\hline No & $15(14.7)$ \\
\hline
\end{tabular}




\section{Duration of the Financial Plan}

$\begin{array}{ll}\text { 1-2 years "Short term" } & 8(9.6) \\ \text { 3-4 years "Medium term" } & 5(6.0) \\ 5 \text { and above "Long term" } & 62(74.7) \\ \text { Expired } & 7(8.4)\end{array}$

Presence of a Fundraising Strategy

Yes

No

\section{Duration of the financial strategy}

1-2 years "Short term"

3-4 years "Medium term"

5 and above "Long term"

Expired

\section{If NGO Invests}

Yes

No

Presence of Investment Plan

Yes

No

Duration of the investment plan

1-2 years "Short term"

3-4 years "Medium term"

5 and above "Long term"

\subsection{NGO Leadership Competences}

This study sought to explore the participants' perception of the leadership competencies that the various NGO leaders possessed. Details of the findings are summarized in Table 4. Findings indicated that the majority of the participants agreed that their NGO leaders were the major source of information on strategic planning (97\%), financial planning (98\%), and were the ones who majorly communicated the NGO mission and Vision (97.1\%). Nevertheless, this study found lower percentages of participants who agreed on investment considerations competencies, where $90.1 \%$ and $91.1 \%$ of the participants thought their NGO leaders were a source of information on investment and were the ones who spearheaded the implementation of the major investment decisions for their NGOs' respectively. Among the organizations with a fundraising strategy, the majority of respondents agreed that their NGO leaders were, also, a major source of that strategy (98\%) and led its implementation (97.1\%). On issues related to funding, nearly $99 \%$ of the participants concurred with the fact that their NGO leaders' were responsible for finding and implementing alternative sources of income. Similarly, there was a strong agreement on competencies related to funding partners where the NGO leader took lead in looking out for funding partners $(99 \%)$ and led the execution of funding opportunities (100\%). 


\section{Macrothink

This study also sought to establish competencies that would result into generation of own income and findings indicated that $94.1 \%$ of the participants agreed that their leaders originated ideas related to income generation activities and as well led their implementation. On competencies related to the NGO leader dealing with the exigencies of complex and difficult external environments, $100 \%$ of the participants agreed that their leaders possessed all the four competencies under responsiveness (See Table 4 below). In the same way, 99\% thought that their leaders were resilient in difficult times and adapted to new and changing environment. Under motivation and empowerment, $99 \%$ of the participants agreed that their leaders possessed those competencies, with the exception of one competence (NGO leader undertaking initiatives to promote/improve staff capability to perform at work) where $100 \%$ of the participants agreed with it (See Table 4 below).

Table 4. Participants' rating of Leadership Competencies in their respective NGOs

\begin{tabular}{|c|c|c|}
\hline Variables & $\begin{array}{l}\text { Agree } \\
n(\%)\end{array}$ & $\begin{array}{l}\text { Disagree } \\
n(\%)\end{array}$ \\
\hline \multicolumn{3}{|l|}{ Strategic, Financial and Investment Planning Considerations } \\
\hline $\begin{array}{l}\text { The NGO leader is the major source of information for the NGO } \\
\text { strategic planning. }\end{array}$ & $98(97)$ & $3(3)$ \\
\hline $\begin{array}{l}\text { The NGO leader is the major source of information for the NGO } \\
\text { Financial planning. }\end{array}$ & $99(98)$ & $2(2)$ \\
\hline $\begin{array}{l}\text { The NGO leader is the one who communicates the NGO mission and } \\
\text { Vision. }\end{array}$ & $99(97.1)$ & $4(2.9)$ \\
\hline \multicolumn{3}{|l|}{ Investment Considerations } \\
\hline $\begin{array}{l}\text { The NGO leader is the major source of information for investment } \\
\text { planning. }\end{array}$ & $91(90.1)$ & $10(9.9)$ \\
\hline $\begin{array}{l}\text { The NGO leader spearheads implementation of major investment } \\
\text { decisions for the NGO. }\end{array}$ & $92(91.1)$ & $9(8.9)$ \\
\hline \multicolumn{3}{|l|}{ Fundraising strategy Considerations } \\
\hline $\begin{array}{l}\text { The NGO leader is the key source of information for the fundraising } \\
\text { strategy. }\end{array}$ & $99(98.0)$ & $2(2)$ \\
\hline $\begin{array}{l}\text { The NGO leader spearheads implementation of the fundraising } \\
\text { strategy. }\end{array}$ & $99(97.1)$ & $3(2.9)$ \\
\hline \multicolumn{3}{|l|}{ Income Diversification Considerations } \\
\hline $\begin{array}{l}\text { The NGO leader takes a lead role in identifying/looking out for } \\
\text { alternative sources of income for the organization }\end{array}$ & $101(99.0)$ & $1(1)$ \\
\hline $\begin{array}{l}\text { The NGO leader spearheads implementation of interventions for } \\
\text { alternative sources of income. }\end{array}$ & $101(99.0)$ & $1(1)$ \\
\hline \multicolumn{3}{|l|}{ Funding Partners } \\
\hline The NGO leader takes a lead role in the lookout for funding partners. & $101(99.0)$ & $1(1)$ \\
\hline $\begin{array}{l}\text { The NGO leader spearheads execution of funding opportunities. } \\
\text { Income Generating Activities }\end{array}$ & $102(100)$ & $0(0)$ \\
\hline The NGO leader originates the NGO's income generating ideas. & $95(94.1)$ & $6(5.9)$ \\
\hline
\end{tabular}




\section{Macrothink}

Journal of Public Administration and Governance

ISSN 2161-7104

2017, Vol. 7, No. 3

The NGO leader spearheads implementation of income generating 95 (94.1) $6(5.9)$ activities.

\section{Responsiveness}

The NGO leader balances competing for demands of time and $102(100) \quad 0(0)$ pressures from a range of stakeholders.

The NGO leader understands and works with whatever resources that $102(100) \quad 0(0)$ is available.

The NGO leader is able to understand and work in difficult and $102(100) \quad 0(0)$ changing environment.

The NGO leader demonstrates willingness to learn and experiment $102(100) \quad 0(0)$ new technologies, reforms, and knowledge.

\section{Attributes of NGO leader}

Resilience during difficult times.

Adaptation to new and changing environment.

\section{Empowerment}

The staff are competent to address the NGO needs

The NGO leader undertakes initiative to promote/improve staff $100(100) \quad 0(0)$ capability to perform at work.

\section{Motivation of Staff}

The staff are motivated to execute the NGO work. $\quad 98$ (99.0) 1 (1)

The NGO leader motivates staff.

$98(99.0) \quad 1(1)$

Note. Variables presented here are those whose Cronbach alpha was above 0.7 for the subscales.

\subsection{Financial Sustainability}

\subsubsection{Trends in NGO Income between 2010 and 2014}

In this study, the average total annual income from all the NGO income sources was found to be $\$ 104,903.39$. In this case, the average annual external donor income, local donor income, and NGO own income were $\$ 70,304.84, \$ 14,179.59, \$ 20,418.96$ and these accounted for $67 \%, 13.5 \%$, and $19.5 \%$ of the average total annual income respectively. Generally, there was a rise in funding from 2010 to 2014 (Figure 1). This total income from all the NGO income sources nearly tripled over the five years from $\$ 53,656.83$ in 2010 to $\$ 140,647.47$ in 2014 . External donor income, local donor income, and own income rose three-fold (\$37,738.59 to $\$ 90,494.11)$, fourfold $(\$ 5,407.84$ to $\$ 23,041.47)$, and twofold $(\$ 10,510.4$ to $\$ 27,111.89)$ respectively in the same period. In addition, the rise in all the NGO incomes was exponential between 2010-2011 and 2013-2014. Meanwhile, between 2011 and 2013 there was a minimal rise in all the NGO incomes. However, only own income dropped between 2012 and 2013. 


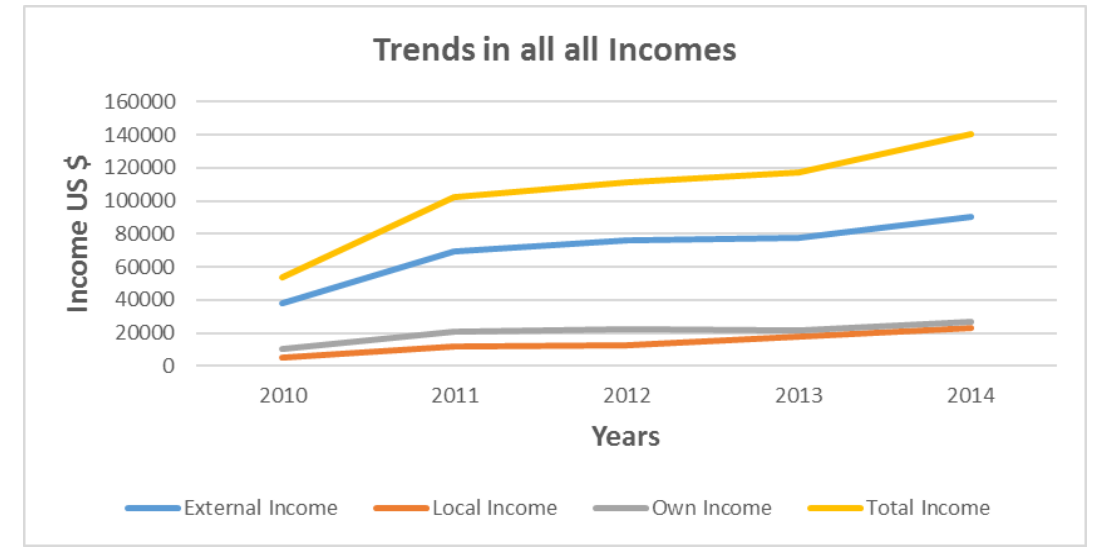

Figure 1. Trends in all donor incomes between 2010 and 2014.

\subsubsection{NGO Donor Dependency Ratio between 2010 and 2014}

Findings indicated that the average donor-dependency ratio was high at $80.54 \%$ over the five-year period. The general trend shows that there was a rise in the donor dependency ratio between 2010 and 2014. However, there was a slight fall in the annual donor dependency ratio from $80.41 \%$ in 2010 to $79.8 \%$ in 2012 (Figure 2). This was followed by a slight rise in the annual donor dependency between 2012 and 2013 (to 81.68\%), before a drop in 2014 (to $80.72 \%)$.

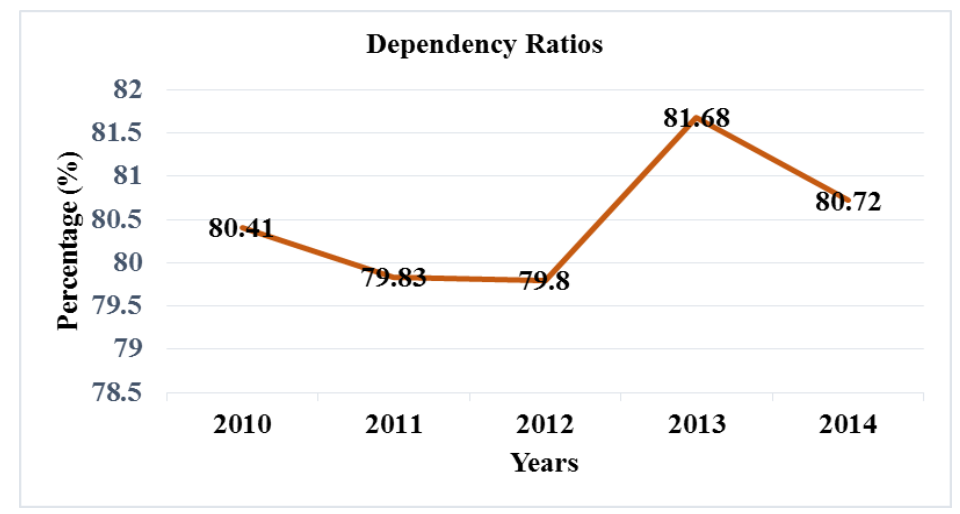

Figure 2. Dependency Ratios between 2010 and 2014.

\subsubsection{NGO Survival Ratio between 2010 and 2014}

The average annual survival ratio over the five-year period was found to be 71.216 days. Over all, there was a fall in the survival ratio between 2010 and 2014. Nonetheless, there was a slight rise in the survival ratio between 2010 and 2012 from 71.5 days to 73.72 days (Figure 3). In addition, the survival ratio reduced between 2012 (73.72 days) and 2013 (to 66.88 days) and raised again in 2014 (70.36 days). 


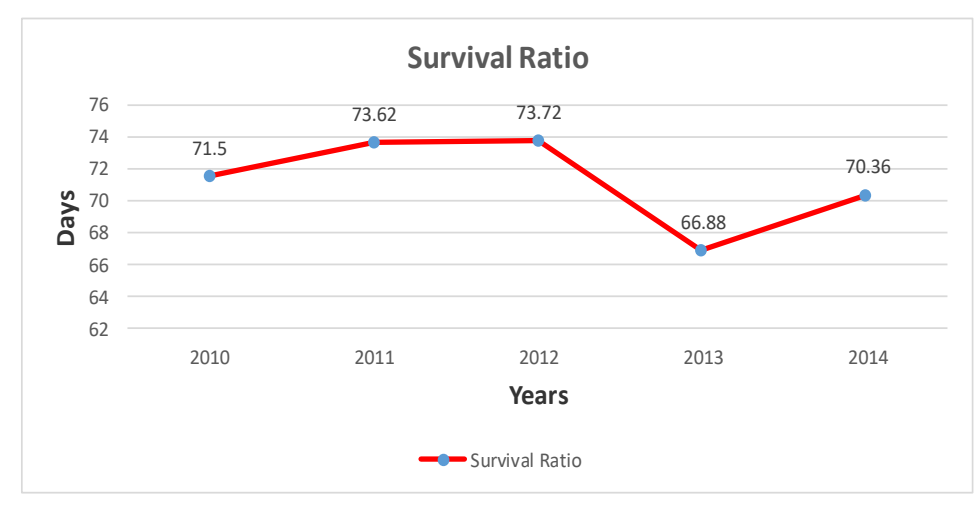

Figure 3. Survival Ratios between 2010 and 2014.

\subsection{Bivariate Associations and Linear Regression Analysis of Leadership Competencies, NGO, and Participant Characteristics against Financial Sustainability Measures}

\subsubsection{Leadership Competencies and Dependency Ratio}

Of all the study variables, adaptation to the new and changing environment $(r=.2, p=0.047)$ and the NGO leader communicating the NGO mission and Vision $(r=.199, p=.045)$ were identified as positively correlating significantly with the dependency ratio. In contrast, the NGO leader understanding and working with whatever resources that are available $(r=-.334$, $p=.001)$ and taking a lead role in the lookout for funding partners $(r=-.249, p=.012)$ were negatively and significantly associated with dependency ratio. Apart from understanding and working with whatever resources were available that had a moderate correlation, the others variables had slightly weaker correlations.

In bivariate linear regression, for every unit increase in the scores (Range 1-5) of the NGO leader understanding and working with whatever resources that were available and taking a lead role in the lookout for funding partners, there was a predicted significant decrease in the dependency ratio by $11.4 \%(\beta=-11.4)$ and $8.99 \%(\beta=-8.99)$ respectively. These variables respectively explained $10.3 \%\left(R^{2}=0.103\right)$ and $5.3 \%\left(R^{2}=0.053\right)$ of the variation in the dependency ratio. Conversely, for every unit increase in the scores (Range 1-5) of the NGO leader adapting to the new and changing environment and communicating the NGO mission and Vision, there was a predicted significant increase in the dependency ratio by $7.1 \%$ and $5 \%$ respectively and theses independent variables explained $3 \%$ of the variation in the dependency ratio.

\subsubsection{NGO, Participant characteristics and Dependency Ratio}

Among NGO and participant characteristics, the type of NGO $(r=.352, p=.000)$, the duration of the strategic plan $(r=.367, p=.000)$, the presence of financial plan $(r=.235, \mathrm{p}=.018)$, and the duration of the financial plan $(r=.386, p=.000)$, correlated positively with dependency ratio. The presence of an active strategic plan $(r=.197, p=.074)$ and the level of education $(r=.194$, $p=.052$ ) were also positive, but, weak correlates with dependency ratio. However, on indicator coding, being a trust and private voluntary organization compared to being another type of NGO ( $r=-.412, p=.000)$, having short $(r=-.213, p=.044)$ and medium strategic plans 
( $r=-.394, p=.000)$ compared to long term strategic plans $(r=.228, p=.030)$, having short $(r=-.333, \mathrm{p}=.002)$ and medium financial plans $(r=-.410, p=.000)$ compared to long term financial plans ( $r=.400, p=.000)$, and the NGO leader possessing a certificate level education or below ( $r=-.226, p=.023)$ compared to having a postgraduate level education $(r=.211$, $p=.034)$ negatively correlated with dependency ratio.

In Bivariate linear regression, unfortunately, all NGO or participant characteristics predicted an increase in the dependency ratio and these were the presence of strategic plan ( $\beta=18.947$, $\left.R^{2}=.125\right)$, type of NGO $\left(\beta=9.191, R^{2}=.124\right)$, level of education $\left(\beta=6.323, R^{2}=.028\right)$, and presence of an active strategic $\left(\beta=14.408, R^{2}=.022\right)$, and financial plan $\left(\beta=13.026, R^{2}=.138\right)$. Nevertheless, being a trust and private voluntary organization compared being another type of NGO $\left(\beta=-36.171, R^{2}=.161\right)$, having short $\left(\beta=-37.714, R^{2}=.035\right)$, and medium strategic plans $\left(\beta=-44.939, R^{2}=.146\right)$ compared to long term strategic plans $\left(\beta=15.238, R^{2}=.041\right)$, having short $\left(\beta=-29.309, R^{2}=.100\right)$, and medium financial plans $\left(\beta=-44.696, R^{2}=.158\right)$ compared to long term financial plans $\left(\beta=24.311, R^{2}=.150\right)$, and the NGO leader possessing a certificate level education and below ( $\beta=-34.747, R^{2}=.041$ ) compared to having a postgraduate level education $\left(\beta=11.399, R^{2}=.035\right)$, significantly predicted a decrease in dependency ratio.

\subsubsection{Leadership Competencies and Survival Ratio}

Slightly weaker, yet positive significant relationships were identified between survival ratio and the NGO leader spearheading the implementation of the major investment decisions for the NGO $(r=.274, p=.006)$, implementing interventions for alternative sources of income $(r=.222, p=.026)$, and understanding and working with whatever resources that are available $(r=.218, p=.028)$. There were also weaker negative significant relationships between survival ratio and the NGO leader being the major source of information for the NGO strategic planning ( $r=-.220, p=.027)$, being a major source of information for the NGO financial planning $(r=-.234, p=.018)$, and adapting to the new and changing environment $(r=.209$, $p=.038)$.

In bivariate linear regression every unit increase in the scores (Range 1-5) of the NGO leader spearheading the implementation of the major investment decisions for the NGO, implementing interventions for alternative sources of income, and understanding and working with whatever resources that are available predicted an increase in the survival ratio by 15.507 days, 14.043 days, and 19.144 days respectively. These independent variables explained $6.6 \%, 4 \%, 3.8 \%$ of the variation in the survival ratio.

Alternatively, for every unit increase in the scores (Range 1-5) of the NGO leader being the major source of information for the NGO strategic planning, being a major source of information for the NGO Financial planning, and adapting to new and changing environment, there was a predicted decrease in the survival ratio by 14.86 days, 17.43 days, and 18.79 days respectively. These independent variables explained $3.9 \%, 4.5 \%$, and $3.4 \%$ of the variation in the survival ratio.

\subsubsection{NGO, Participant characteristics and Survival Ratio}

Among participant and NGO characteristics, the duration of the NGO leader at the current 
NGO $(r=.333, p=.001)$, the presence of the investment plan $(r=.386, p=.000)$, and the current governance of the NGO $(r=.235, p=.019)$ positively correlated with survival ratio. Contrariwise, the duration of the financial plan $(r=-.347, p=.001)$, the type of the NGO $(r=-.325, p=.001)$, and the level of education $(r=-.361, p=.000)$ also significantly and moderately but negatively correlated with survival ratio. Other competencies as shown in Table 4 above did not significantly correlate with survival ratio. Indicator coding showed that having long term strategic plans $(r=-.260, p=.018)$ compared to short-term strategic plans $(r=.289, p=.006)$, having long-term financial plans $(r=-.260, p=.009)$ compared to short-term financial plans $(r=.474, p=.000)$, and the NGO leader possessing postgraduate level education ( $r=-.315, p=.001)$, compared to having a certificate level education or below $(r=.369, p=.000)$, and the NGO leader having worked for less than 5years at an NGO $(r=-.298, p=.002)$, negatively correlated with survival ratio. Only management committee as a governance structure as compared to other forms of governance structures correlated weakly but positively with survival ratio $(r=.216, p=.032)$.

Bivariate linear regression showed that, the NGO and personal characteristics that predicted an increase in survival ratio included the duration of NGO leader at the NGO $(\beta=24.484$, $\left.R^{2}=.102\right)$, the presence of the investment plan $\left(\beta=62.439, R^{2}=.140\right)$, and who governed the NGO $\left(\beta=21.051, R^{2}=.045\right)$. Meanwhile, the duration of the financial plan $(\beta=-27.825$, $\left.R^{2}=.110\right)$, the type of the NGO $\left(\beta=-6.457, R^{2}=.008\right)$, and the level of education $(\beta=-30.349$, $\mathrm{R} 2=.122)$, predicted a decrease in survival ratio. Results also showed that having long-term financial plans $\left(\beta=,-40.398 R^{2}=.056\right)$ compared to short-term financial plans $(\beta=106.586$, $\left.R^{2}=.215\right)$, the NGO leader possessing postgraduate level education $\left(\beta=-43.424, R^{2}=.090\right)$ compared to certificate level education and below $\left(\beta=145.308, R^{2}=.128\right)$, the NGO leader having worked for less than 5years at an NGO ( $\left.\beta=-48.304, R^{2}=.080\right)$, predicted a decrease in survival ratio. Again, only management committee as a governance structure as compared to others forms of governance structures predicted an increase in the survival ratio $(\beta=47.838$, $\left.R^{2}=.037\right)$.

\subsubsection{Leadership Competencies and Total NGO Income}

The two competencies that were found to be significant but weakly and negatively associated with total NGO income included the NGO leader being the major source of information for the NGO strategic planning ( $r=-.232, p=.020)$, and the NGO leader being the one who communicates the NGO mission and Vision $(r=-.195, p=.050)$.

Bivariate linear regression showed that for every unit increase in the scores (Range 1-5) of the NGO leader being the major source of information for the NGO strategic planning and being the one who communicates the NGO mission and Vision, there was a predicted decrease in the total NGO income by $\$ 18651.412$, and $\$ 15831.927$ respectively. These independent variables explained $4.4 \%$ and $2.8 \%$ of the variation in the total NGO income. In this study, none of the leadership competencies correlated or predicted an increase in total NGO Income. 


\section{5.6 NGO, Participant Characteristics, and Total NGO Income}

Variables under NGO and personal characteristics that were found to negatively correlate with NGO total income included the duration of the strategic plan $(r=-.362, p=.000)$ and the duration of the financial plan $(r=-.275, p=.012)$. On the other hand, if an NGO had investments ( $r=.226, p=.022)$, had an investment plan $(r=.233, p=.022)$, had a fundraising Strategy $(r=.203, p=.042)$, the region where an NGO was located $(r=.303, p=.002)$, the duration of the NGO leader at an NGO $(r=.299, p=.003)$, and the governance structure of the NGO $(r=.304, p=.002)$ correlated positively with total NGO income. However, when these variables were indicator coded, the NGOs that were located in the western part of Uganda $(r=.415, p=.000)$ compared to those in the north $(r=-.238, p=.016)$ and having short-term strategic $(r=.360, p=.000)$ and financial $(r=.291, p=.008)$ plans positively correlated with total NGO income. Meanwhile, the NGO leader having worked at the NGO for less than 5years negatively correlated with total NGO income $(r=-.187, p=.031)$.

In bivariate regression, if an NGO invested, had an investment plan, and had a fundraising Strategy compared to those that did not have them, there was a predicted increase in the total NGO income by $\$ 36,309.083, \$ 45,331.563$, and $\$ 32,815.891$ respectively. These independent variables explained $4.2 \%, 4.4 \%$, and $3.2 \%$ of the variation in the total NGO income respectively. Similarly, if the NGO leader had worked at the NGO for greater than 5years and the NGO was from the western part of Uganda, there was a predicted increase in the total NGO income by $\$ 26,116.576$, and $\$ 17,286.355$ respectively. These independent variables explained $8 \%$ and $8.3 \%$ of the variation in the Total NGO income. Nevertheless, the NGO being located in the western part of Uganda $\left(\beta=69,810.187, R^{2}=.164\right)$, compared to the north $\left(\beta=-44,429.441, R^{2}=.047\right)$, and having short-term strategic $\left(\beta=19,6267.389, R^{2}=.120\right)$, and financial plans $\left(\beta=78,739.377, R^{2}=.073\right)$ as compared to those with medium and long term plans, predicted an increase in total NGO income. Lastly, the NGO leader working at the NGO for less than 5years predicted a decrease in total NGO income $(\beta=-36,307.179$, $\left.R^{2}=.025\right)$.

\subsection{Multiple Linear Regression Analysis of Leadership Competencies and NGO Characteristics That Predict Dependency Ratio}

Standard multiple regression was used to determine the influence of leadership competencies, NGO, and personal characteristics on dependency ratio of an NGO. The model explained $37.1 \%(F(5,103)=11.486, P=.000)$ of the variance in dependency ratio and thus slightly over $60 \%$ of the dependency ratio is explained by factors not included in the model. In the final model, two competencies and three NGO characteristics were found to be statistically significant predictors of dependency ratio. Finding indicated that for every unit increase in the scores (Range 1-5) of the NGO leader understanding and working with whatever resources that are available, there is $9.802 \%$ decrease in the dependency ratio (Table 5). On the other hand, higher scores on the NGO leader being the one who communicates the NGO mission and Vision, there was a predicted increase the dependency ratio by $5.172 \%$. The type of NGO the participant came from and the NGO leader being able to understand and work with whatever resources made the strongest contribution in explaining the dependency ratio 
by $33.8 \%$ and $28.7 \%$ (see Table 5 , under beta).

In sum, the model suggests that a higher percentage of dependency ratio is strongly predicted by the NGO leader communicating the NGO mission and Vision, type of NGO, the presence of the active strategic plan, and the duration of the strategic plan (Table 5). However, the NGO leader being able to understand and work with whatever available resources reduces the dependency ratio.

Table 5. Multiple Linear Regression Analysis of Leadership Competencies and NGO Characteristics that Predict Dependency Ratio

\section{Variables}

Leadership Competencies.

The NGO leader is the one who communicates the NGO mission and Vision.

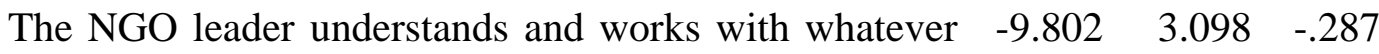

$\begin{array}{lll}5.172 & 2.311 \quad .196\end{array}$

.028 resources that is available.

\section{NGO Characteristics.}

Type of NGO

Presence of Active Strategic Plan.

Duration of the Strategic Plan.

$\begin{array}{lll}14.322 & 4.682 & .277\end{array}$

Note: Unstandardized coefficients $(\beta)$ reported were significant at 0.05 or 0.01 .

\subsection{Multiple Linear Regression Analysis of Leadership Competencies, Participants, and NGO} Characteristics That Predict NGO Survival Ratio

Standard multiple regression methods were applied to assess the influence of leadership competencies, NGO and participants' characteristics on survival ratio of an NGO. The model accounted for $34 \%(F(4,101)=10.897, P=.000)$ of the variance in survival ratio and thus nearly $66 \%$ of the survival ratio is explained by factors not included in the model. In the final model, one leadership competence, two NGO characteristics, and participant characteristic were found out as statistically significant predictors of survival ratio. The NGO leader spearheading the implementation of major investment decisions for the NGO was found out as the only significant predictor of an increase in survival ratio. $(\beta=15.720, P=.004)$. Suggesting that for every one-unit increase in the rating of the NGO leader spearheading the implementation of major investment decisions for the NGO, the survival ratio increases by 15.720 days. Meanwhile, the presence of investment plan and the duration of the NGO leader at the current NGO predicted an increase in survival ratio by 47.158 days and 19.614 days respectively. Additionally, the presence of the Investment plan and the NGO leader spearheading the implementation of major investment decisions made the strongest contribution in explaining the survival ratio by $29.2 \%$ and $28 \%$ respectively (see Table 6 , under beta). With regard to reducing the survival ratio, the duration of the financial plan reduced the survival ratio by 23.545 days. 


\section{Ml Macrothink}

Journal of Public Administration and Governance

ISSN 2161-7104

2017, Vol. 7, No. 3

Table 6. Multiple Linear Regression Analysis of Leadership Competencies and NGO Characteristics that Predict NGO Survival Ratio

\begin{tabular}{|c|c|c|c|c|}
\hline \multicolumn{5}{|l|}{ Variables } \\
\hline & $\beta$ & $S E$ & Beta & $P$ \\
\hline \multicolumn{5}{|l|}{ Leadership Competencies. } \\
\hline $\begin{array}{l}\text { The NGO leader spearheads implementation of major } \\
\text { investment decisions for the NGO. }\end{array}$ & 15.720 & 5.230 & .280 & .004 \\
\hline \multicolumn{5}{|l|}{ NGO Characteristics. } \\
\hline Duration of the Financial Plan. & -23.545 & 8.173 & -.273 & .005 \\
\hline Presence of Investment plan. & 47.158 & 15.265 & .292 & .003 \\
\hline \multicolumn{5}{|l|}{ Participant Profile. } \\
\hline Duration at Current NGO. & 19.614 & 6.874 & .270 & .006 \\
\hline
\end{tabular}

Note: Unstandardized coefficients $(\beta)$ reported were significant at 0.05 or 0.01 .

3.8 Multiple Linear Regression Analysis of NGO and Participant Characteristics that Predict Total NGO Income

Standard multiple regression methods were also conducted to assess the influence of leadership competencies, NGO, and participants' characteristics on total NGO income. The model explained $30.3 \%(F(4,103)=10.575, P=.000)$ of the variance in total NGO income and thus nearly $70 \%$ of the total NGO come is explained by factors not included in the model. In the final model, three NGO characteristics and one participant characteristic were found out as statistically significant predictors of the total NGO income. In the final regression model, no leadership competences predicted the NGO total income. The region where the NGO was located, an NGO investing, and the NGO leader's duration at the NGO predicted an increase in NGO total income by $\$ 12,124.703, \$ 47,993.167$, and $\$ 24,291.671$ respectively. Meanwhile, the duration of the strategic plan predicted a decrease in total NGO income by $\$ 52,596.2$ and this variable had the strongest contribution in explaining the NGO total income by $33.1 \%$ (see Table 7 , under beta).

Table 7. Multiple Linear Regression Analysis of NGO and Participant Characteristics that Predict Total NGO Income

\begin{tabular}{lllll}
\hline Variables & \multicolumn{3}{c}{} & \\
\hline \multicolumn{1}{l}{ NGO Characteristics } & $\boldsymbol{\beta}$ & $\boldsymbol{S}$ & $\boldsymbol{B}$ & $\boldsymbol{P}$ \\
Region of NGO & & & & \\
If NGO invests & 12124.703 & 5311.565 & .213 & .025 \\
Duration of the Strategic Plan & 47993.167 & 14448.333 & .299 & .001 \\
Participant Profile & -52596.24 & 14463.588 & -.331 & .000 \\
Duration at current NGO & & & & \\
\hline
\end{tabular}

Note: Unstandardized coefficients $(\beta)$ reported were significant at 0.05 or 0.01 . 


\section{Discussion}

This study is one of the first to assess the relationship between leadership competencies and financial sustainability measures in sub-Saharan Africa. We found out that there was a very strong agreement by participants on possession of the leadership competencies among NGO leaders in Uganda ranging from $90.1 \%$ to $100 \%$. However, that agreement was highest among competencies related to the responsiveness of NGO leaders to changing funding environment and low among competencies related to investment considerations and alternative sources of income. One possible reason for this low rating on investment and income generating activities leadership competencies could have arisen from the fact that nearly $50 \%$ of the NGOs surveyed did not invest some of their funding and a few had income generating activities. Nevertheless, this study finding is consistent with research findings by Hailey (2006) who revealed that NGO leaders demonstrated an unusually broad range of competencies that include self-awareness and self-management. Also, Bolton \& Abdy (2003) found out that leaders had the ability to communicate NGO vision, identifying and exploiting opportunities, inspiring teams, motivating NGO staff, creating and managing donor relationship (Bolton \& Abdy, 2003). However, we were unable to find previous studies that rated the possession of these competencies among NGO leaders.

On financial sustainability, our findings show that the average annual external donor income, local donor income, and own income accounted for $67 \%, 13.5 \%$, and $19.5 \%$ of the average total annual income respectively. In addition, there was a general there was a rise in funding from 2010 to 2014. On the contrary, previous studies in Zimbabwe, Kenya, and Ghana conducted showed a declining external donor funding of NGOs mostly attributed to the global economic crisis (Gyamfi, 2010; Manyeruke (2012) Njoroge 2013; Saungweme, 2014; Waiganjo et al. 2012). Possibly, the cordial relationship between Uganda and the other donor countries coupled with the service gap left by the government, the high rating on the majority of the leadership competencies, and majority of the NGOs being founded and run by the same NGO leaders may explain the rise in the donor funding in Uganda during the period of 2010-2014. The average annual survival ratio over the five-year period for NGOs was found to be 71.216 days. Over all, there was a fall in the survival ratio between 2010 and 2014. This, therefore, means that NGOs' can hardly survive beyond two months if all its funds are dried up and if there are no donations received during the year. Similarly, findings by Saungweme (2014) established very low survival ratios for NGOs, the highest being 22.01 days. In this study, the average donor-dependency ratio was found to be high at $80.54 \%$ over the five-year period. The general trend also shows that there was a rise in the donor dependency ratio between 2010 and 2014. Above all, this donor dependency was coupled with a low investment by NGOs where $50 \%$ and $21.9 \%$ of the NGOs' invested and had an investment plan respectively. Similarly, study findings by Waiganjo (2012) in Kenya revealed $70 \%$ of NGO funding was from external donors while Saungweme (2014) established that NGOs in Zimbabwe had very high donor dependency ratios, the lowest being 93.97\%. Saungweme (2014) also found out that $71 \%$ of the organizations did not have investment/financial plans and yet over 82 percent of NGOs noted that investment planning was important to the sustainable funding of their organizations. 
Although many leadership competencies significantly correlated with the three financial sustainability measures, only two of those competencies provided a meaningful interpretation in the final model and these included of the NGO leader understanding, working with whatever resources that are available and the NGO leader spearheading the implementation of major investment decisions. The NGO leader understanding and working with whatever resources that are available, predicted a $9.802 \%$ decrease in the dependency ratio. Meanwhile, the NGO leader spearheading the implementation of major investment decisions for the NGO predicted an increase in survival by 15.720 days. Additionally, none of the leadership competencies did have the influence on the total NGO income. However, we did not access any previous study to make comparisons.

\subsection{Implications and Recommendations}

A local NGO possessing an investment and implementing it are two separate matters. NGOs may establish the investment plan either as a basis of attracting donor funding or as a funding requirement by the donor. In either case, what remains important is the implementation of the investment or financial plan that will have a bearing on sustainable funding on the NGO. Therefore, NGOs should invest in investment planning and establish alternative sources of funding, as well as commit to implementation of those plans to increase NGO funding and become sustainable. The investment plans should be able to attract donor funding, as well as, help in diversification of income from multiple sources.

These study findings, underpin the importance of the responsiveness of the NGO leader to the changing funding environment, and also reveals the need for dynamic, innovative and proactive leadership in the NGO sector. It is therefore imperative for funders and NGOs to adopt and build the capacity of leaders in investment and optimal resource utilization (effective and efficient resource management) to become sustainable with respect to funding.

The general rise in NGO funding between 2010 and 2014 can be attributed to commitment in donor funding of NGO activities in Uganda. It further points to a recovery in the global economic position since the financial crisis 2008/9. The global economic recovery is an opportunity for financial resource mobilization of the NGO sector in Uganda and the world over. The $13.5 \%$ local contribution as compared to $67 \%$ external donor funding position reveals a very low local funding and fundraising culture in Uganda. Thus, there is need to cultivate fundraising culture in Uganda to boost local income and improve sustainable funding of NGOs.

When compared to the findings by Saungweme (2014) among NGOs in Zimbabwe for 2012, the average annual survival ratio over the five-year period for NGOs in Uganda was higher by 49.206 days. However, this survival ratio is still low and depicts limited capacity of NGO leaders to mobilize resources to sustain their activities. Henceforth, there is need to boost local sources of funding especially income Generating Activities (IGAs) to improve survival of NGOs in Uganda. NGOs should prioritize investments in IGAs as core sources of funding and donors should build the capacity of and support NGOs to establish IGAs to reduce over-dependence on a single source of funding. 
This study, like in previous research findings indicates a prevalently high donor-dependency ratio pointing to a persistent donor-dependency syndrome for developing countries, especially, in Africa and Uganda in particular. The high donor-dependence is a threat to NGO independence in terms of agenda implementation. If not overcome, the NGOs will continue being viewed as sub-contractors of international NGOs and therefore a risk of loss of local legitimacy and relevance in serving an international or external agenda. Therefore, there is a need for deliberate government policies to support NGOs preferably through their network organizations, where governments would allocate a sufficient budget and resources for implementation of NGOs' agenda that is in line with the national development plans and priorities. This will enhance NGO participation in national development agenda especially to serve the underserved and those citizens that are unable to access government services, thereby strengthen partnership with national governments by serving local/national agenda and subsequently reducing donor dependency. Lastly, further research in other countries is needed to establish the leadership competencies of NGO leaders and how they influence sustainable funding of NGOs. In addition, further research utilizing a larger sample size is also needed to develop a tool to measure NGO leadership competencies.

\subsection{Limitations of the Study}

This study had some limitations. The respondents of this study were majorly NGO leaders and this self-report may have been over or understated. In addition, the majority of NGOs provided categorized figures of their annual incomes. Computing categorized data into continuous data may have led to the loss of some meaningful data.

\section{Conclusion}

This study suggests that the NGO leader understanding, and working with any available resources and the NGO leader spearheading the implementation of major investment decisions are key factors influencing financial sustainability of NGOs.

\section{Acknowledgement}

Special thanks go to Fulufhelo Godfrey Netswera and Edward Malatse Rankhumise, of Tshwane University of Technology.

\section{References}

Barr, A., Fafchamps, M., \& Owens. M. (2003). Non-governmental organizations in Uganda: A report to the Government of Uganda Centre for the Study of African Economies, Department of Economics Oxford University. Retrieved from http://www.csae.ox.ac.uk/reports.

Bolton, M., \& Abdy, M. (2003). Leadership. London, England: ACEVO.

Burger. R., Owens. T. (2012). The Survival Prospects of African Nongovernmental Organizations (Research Paper No. 11/07).

Gyamfi, P. (2010). Financing local non-governmental organizations in Ghana: issues and challenges. Master's thesis. Accra: Kwame Nkrumah University. 
Hailey, J. (2006). NGO leadership development. Praxis Paper No. 10.

Hailey, J., \& James, R. (2004). Trees die from the top: International perspectives on NGO leadership development. Voluntas, 15(4), 343-353.

https://doi.org/10.1007/s11266-004-1236-8

James, R. (2005a) The Crushing Impact of HIV/AIDS on Leaders in Malawi, Praxis Note No.10, Oxford: INTRAC www.intrac.org/pages/praxis_notess Accessed: 20 June 2014.

James, R. (2005). Autocratics Anonymous: A Controversial Perspective on Leadership Development. Praxis Note No. 14.

Lewis, D. (2001). Management of Non-Governmental Development Organizations: An Introduction. London, England: Routledge. https://doi.org/10.4324/9780203002162

Manyeruke, C. (2012). Mitigating the effects of the global financial crisis in Zimbabwe: the alternative strategies for the non-governmental organizations. African Journal of Social Sciences, 2(2), 1-9.

Mugenda , O., M. \& Mugenda, A., G. (2003). Research Methods: Quantitative and Qualitative Approaches. Nairobi, Kenya: African Centre for technological studies.

Njoroge, G.B. (2013). An investigation on the factors influencing the sustainability of NGOs in Kenya. Masters of Science thesis. Nairobi: University of Nairobi.

NORAD. (2002). A report of a Study on the civil society in Uganda for the Royal Norwegian embassy in Uganda. Retrieved from

https//www.norad.no/en/toolpublications/publications/2009

Sanjeev, G., Powell, R., \& Yang, Y. (2006). Macroeconomic Challenges of Scaling Up Aid to Africa (Working Paper No. WP/05/179.). Retrieved from https://books.google.com

Saungweme, M. (2014). Factors influencing the financial sustainability of local NGOs: the case of Zimbabwe (Doctoral dissertation). Stellenbosch University: Stellenbosch. Retrieved from http//hdl.handle.net/10019.1/97293

Sharma, P. (2012). Performance measurements in NGOs. The Management Accountant.1442-1444

Sooryamoorthy, R., \& Gangrade, K., D. (2001). NGOs in India: A Cross Sectional Study. Retrieved from www.bokus.com/bok

Sweat, S., A. \& Martin K. S. (2008). Data analysis with SPSS: A first course in applied statistics. Boston, USA: Pearson Education, Inc.

USAID. (2010). 2009 NGO Sustainability Index for Sub-Sahara Africa. Retrieved from https//www.usaid.gov/africa-civil-socety/2009.

Waiganjo, E.W., Ng'ethe, J.M. and Mugambi, D.N. (2012). An investigation into the strategies adopted by the non-governmental organization in Kenya to increase financial sustainability. International Journal of Current Research, 4(4), 74-78. 


\section{Macrothink}

Journal of Public Administration and Governance ISSN 2161-7104 2017, Vol. 7, No. 3

Wamai, N., Walera, I., \& Wamai G. (2002): The Role of Non-Governmental Organizations (NGOs) in Social Development. A study of Health Sector NGOs in Mbale and Mubende Districts, 1997. Retrieved from Stanford University libraries website: https://searchworks.standford.edu

Weerawardena J., McDonald R., \& Mort G. (2009). Sustainability of nonprofit organizations: An empirical investigation. Journal of World Business 45, 346-356. https://doi.org/10.1016/j.jwb.2009.08.004

\section{Copyright Disclaimer}

Copyright for this article is retained by the author(s), with first publication rights granted to the journal.

This is an open-access article distributed under the terms and conditions of the Creative Commons Attribution license (http://creativecommons.org/licenses/by/4.0/). 